\title{
Volatile Oil Constituents of Rosa canina L.: Quality As Affected by the Distillation Method
}

\author{
Karim Hosni, ${ }^{1}$ Amel Kerkenni, ${ }^{2}$ Wafa Medfei, ${ }^{2}$ Nadia Ben Brahim, ${ }^{3}$ and Houcine Sebei ${ }^{2}$ \\ ${ }^{1}$ Laboratoire des Substances Naturelles, Institut National de Recherche et d'Analyse Physico-chimique (INRAP), \\ Technopôle de Sidi Thabet, Ariana 2020, Tunisia \\ ${ }^{2}$ Département de Production Agricole, École Supérieure d'Agriculture de Mograne, Zaghouan 2021, Tunisia \\ ${ }^{3}$ Département de Botanique et des Plantes d'Ornement, Institut National de Recherche Agronomique de Tunis, Tunis 1080, Tunisia \\ Correspondence should be addressed to Karim Hosni, hosni_karim@voila.fr
}

Received 30 September 2010; Revised 10 November 2010; Accepted 9 December 2010

Academic Editor: William N. Setzer

Copyright (๑) 2010 Karim Hosni et al. This is an open access article distributed under the Creative Commons Attribution License, which permits unrestricted use, distribution, and reproduction in any medium, provided the original work is properly cited.

The volatile oils of R. canina flowers were isolated by hydrodistillation (HD) and traditional dry distillation (DD) and analyzed by HRGC-FID and GC-MS. Compared to HD, DD at $50^{\circ} \mathrm{C}$ leads to the isolation of high quality oil which contains the highest content of oxygenated compounds (83\%). The main components are the 2-phenethyl alcohol and eugenol. The percentage of the 2-phenethyl alcohol, a highly desirable component in rose oil, was significantly higher (58.4\%) in DD extract when compared to that of $\mathrm{HD}$ one $(13.6 \%)$. As temperature increased $\left(100^{\circ} \mathrm{C}\right)$ during $\mathrm{DD}$, the oil quality decreased. The most significant changes were observed in 2-phenethyl alcohol percentage (4.5\%). Moreover, an increase of alkanes/alkenes and the production of furan derivatives were observed. So, DD at moderate temperature $\left(50^{\circ} \mathrm{C}\right)$ seemed more suitable to improve the volatile oil quality and hence, to make more value of $R$. canina.

\section{Introduction}

Rosa canina L. (Rosaceae), known as "dog rose", is a prickly shrub (1-3 m high) with fragrant pink or white flowers. This species has been evaluated for its food-related biological properties, and a multiple functional uses have been suggested. For example, teas made from the fruits of this plant called "rose hips" have mild laxative and diuretic tendencies [1]. They have also been used for the prevention and the treatment of common cold, influenza-like infections, infectious diseases, for vitamin $\mathrm{C}$ deficiency, fever, general exhaustion, gastric spasms, prevention of gastritis and gastric ulcers, diarrhea, gallstones and gallbladder discomforts, urinary tract diseases and discomforts, inflammatory disorder, arthritis, nephritis, rheumatism, gout, sciatica, diabetes, inadequate peripheral circulation, and lung ailments [2].

For nutritional purposes, rose hips are used for the production of marmalade, jam, dessert soup, wine and juices [2]. Ground in a hand mill and cooked with milk, they could be used as children's snack and baby food as reported by the latter authors. In Tunisia, R. canina known as "Nesri" is used for the production of aromatic water called "Nesri water". The latter, usually obtained by hydrodistillation of the flowers, is highly appreciated and consumed as healthpromoting product as well as to prevent cardiovascular diseases, although no pharmacological investigations have supported this application so far. Additionally, this aromatic water is widely used as a flavouring agent of drinks, for the production of jam, marmalade, and the special traditional cake of Zaghouan (traditional area of cultivation of $R$. canina in north eastern Tunisia).

The functional properties of $R$. canina were attributable to a wide array of bioactive ingredients such as minerals, fatty acids, ascorbic acid, phenols, flavonoids, tannins, and sugar [3]. Volatile oils, responsible for the unique and pleasant flavour of $R$. canina were partially evolved in these actions [4]. Previous phytochemical studies on volatile oils of different Rosa species have led to the identification of more than 400 compounds, classified into several chemical groups including hydrocarbons, alcohols, esters, aromatic ethers, aldehydes, and norisoprenoids [5]. Traditional methods for the isolation of the volatile oils from rose flowers include 
solvent extraction, steam distillation, or water distillation [6]. Dry distillation is also used for the extraction of high quality essential oil from rose petals [7]. This method which consists in heating the raw material at moderate temperature without solvent (water or organic solvent) is successfully used in the Arabic gulf countries namely, Oman sultanate.

Despite that the hydrodistillation is the most usual method for the extraction of the aromatic water; there are no critical reports on its effects on the product quality. With respect to this topic, the present contribution was aimed at the investigation of the chemical composition of the floral aromatic water obtained from $R$. canina by two traditional methods; hydrodistillation (HD) and dry distillation (DD). These data are useful since they provide information about the volatile constituents of $R$. canina from Tunisian origin that has not been reported to date, and to assess the quality profile of this product traditionally used as functional food.

\section{Materials and Methods}

2.1. Reagents. Hexane and $n$-pentane of analytical grade were purchased from LabScan (Dublin, Ireland); anhydrous $\mathrm{Na}_{2} \mathrm{SO}_{4}$ and $n$-alkanes $\left(\mathrm{C}_{6}-\mathrm{C}_{40}\right)$ were purchased from Fluka (Buchs, Switzerland). The hexan-1-ol used as internal standard for the quantification of the volatile constituents was purchased from Merck (Shuchardt, Germany).

2.2. Plant Material. Flowers of R. canina L. were harvested from cultivated plants grown in the dog rose biodiversity garden (Mograne, Tunisia; latitude $36^{\circ} 26^{\prime}(\mathrm{N})$; longitude $10^{\circ} 05^{\prime}$ (E); altitude $156 \mathrm{~m}$ above sea). Means annual precipitation and temperature are $502 \mathrm{~mm}$ and $17.9^{\circ} \mathrm{C}$, respectively.

\subsection{Isolation Procedures}

2.3.1. Hydrodistillation (HD). Fresh flowers ( $100 \mathrm{~g}$ ) were subjected to conventional hydrodistillation for $1 \mathrm{~h}$ using a simple laboratory Quikfit apparatus which consisted of a $2000 \mathrm{~mL}$ distillation flask, a condenser, and a receiving vessel. The obtained distillate was extracted twice with $n$-pentane and dried over anhydrous sodium sulphate $\left(\mathrm{Na}_{2} \mathrm{SO}_{4}\right)$. Choice of the solvent was based on its ability to extract the major constituents of the essence without loss of the high volatile components $[8,9]$. The $n$-pentane extract of aromatic water was then concentrated, at $35^{\circ} \mathrm{C}$ using a Vigreux column at atmospheric pressure and subsequently analyzed.

2.3.2. Dry Distillation (DD). Fresh flowers ( $100 \mathrm{~g}$ ) were put in a beaker $(2 \mathrm{~L})$ without water and closed with airtight conical lip which contains cold water for the condensation of the volatile saturated steam. The distillates were recovered in a glass funnel $(50 \mathrm{~mL})$ inside the beaker. The system was heated at 50 and $100^{\circ} \mathrm{C}$ in order to study the effect of higher temperature on the chemical composition of the aromatic water. The distillates were subjected to a liquid/liquid extraction using $n$-pentane, dried over anhydrous $\mathrm{Na}_{2} \mathrm{SO}_{4}$ and concentrated as described above (cf. Section 2.3.1).

\subsection{Chromatographic Analysis}

2.4.1. High Resolution Gas Chromatography (HRGC-FID). Gas chromatography analyses were carried out on a Shimadzu HRGC-2010 gas chromatograph (Shimadzu Corporation, Kyoto, Japan) equipped with flame ionisation detector (FID), Auto-injector AOC-20i, auto-sampler AOC20s. A polar column HP-Innowax $(30 \mathrm{~m} \times 0.25 \mathrm{~mm}, 0.32 \mu \mathrm{m}$ film thickness) was used. The oven temperature was held at $50^{\circ} \mathrm{C}$ for $10 \mathrm{~min}$ then programmed at $2^{\circ} \mathrm{C} / \mathrm{min}$ to $190^{\circ} \mathrm{C}$. The injector and detector temperatures were programmed at $230^{\circ} \mathrm{C}$. The flow of the carrier gas (Nitrogen) was $1.2 \mathrm{~mL} / \mathrm{min}$, the split ration was $1: 20$, and the injection volume for all extract samples was $0.5 \mu \mathrm{L}$.

2.4.2. Gas Chromatography-Mass Spectrometry (GC-MS). The GC-MS analyses were performed on a gas chromatograph HP 6890 (II) interfaced with an HP 5973 mass spectrometer (Agilent Technologies, Palo Alto, Ca, USA) with electron impact ionization $(70 \mathrm{eV})$. An HP-5MS capillary column $(60 \mathrm{~m} \times 0.25 \mathrm{~mm}, 0.25 \mu \mathrm{m}$ film thickness $)$ was used. The column temperature was programmed to rise from $40^{\circ} \mathrm{C}$ to $280^{\circ} \mathrm{C}$ at a rate of $5^{\circ} \mathrm{C} / \mathrm{min}$. The carrier gas was helium with a flow rate of $1.2 \mathrm{~mL} / \mathrm{min}$. Scan time and mass range were $1 \mathrm{~s}$ and $50-550 \mathrm{~m} / \mathrm{z}$, respectively. The $n$-pentane extract of aromatic water $(1 \mu \mathrm{L})$ was automatically injected in the splitless mode.

2.4.3. Compound Identification. The volatile compounds were identified by: comparison of their retention index (RI) relative to $\left(\mathrm{C}_{6}-\mathrm{C}_{40}\right) n$-alkanes with those of literature and/or with those of authentic standards available in our laboratory, and by matching their mass spectral fragmentation patterns with corresponding data (Wiley 275.L library) and other published mass spectra [10] and by comparison of their retention indices with data from the Mass Spectral Library “Terpenoids and Related Constituents of Essential Oils” (Dr. Detlev Hochmuth, Scientific consulting, Hamburg, Germany) using the MassFinder 3 software (www.massfinder.com/). Quantitative data were obtained from the electronic integration of the FID peak areas without the use of the correction factors.

2.5. Statistical Analysis. The experiment and analytical determinations were carried out in triplicate. The significant differences among extract samples for each the constituents were determined by one-way analysis of variance (ANOVA) using Duncan's multiple range test at the significance level of $P<.05$.

\section{Results and Discussion}

3.1. Chemical Composition of the Aromatic Water from $R$. Canina. The total ion chromatograms (TIC) of the $n$-pentane extracts of aromatic water obtained from $R$. canina flowers by $\mathrm{HD}, \mathrm{DD}$ at moderate $\left(50^{\circ} \mathrm{C}\right)$ and at higher temperature $\left(100^{\circ} \mathrm{C}\right)$ are displayed in Figure 1. Components were identified by using the combination of retentions index 
value and mass spectral matching against library standards, and they are summarized in Table 1 in order of their elution on HP-5MS column. Altogether, 27 compounds among them, 9 alkanes, 3 alkenes, 3 sesquiterpene hydrocarbons, 5 alcohols, 3 furan derivatives, 2 monoterpene hydrocarbons, 1 oxygenated sesquiterpenes, and 1 isoprenoid have been identified, amounting to $92.4,89.8$, and $73.9 \%$ of the total $n$ pentane extract of aromatic water obtained by $\mathrm{HD}$ and $\mathrm{DD}$ at $50^{\circ} \mathrm{C}$ and at $100^{\circ} \mathrm{C}$, respectively. In earlier compositional study on R. canina, 18 and 6 compounds were identified in the essential oils obtained by superheated water and soxhlet extraction, respectively [6]. Therefore, many identified components of the $n$-pentane extract of aromatic water are being reported for the first time. These components are (E)-3-hexenol, $\alpha$-pinene, linalool, eugenol, $\beta$-caryophyllene, $\alpha$-guaiene, $\beta$-ionone, $\delta$-guaiene, caryophyllene oxide, 1 heptadecene, heptadecane, 8-heptadecene, nonadecane, 1nonadecene, docosane, tricosane, tetracosane, pentacosane, and hexacosane. Most of them had been previously reported in other Rosa species such as R. centifolia [11], R. rugosa [12], $R$. damescena [13], R. abyssinica [14], $R$. brunonii [15], and R. hybrida [16].

For convenience reasons, and to facilitate the comparison between the present results with those previously reported, we firstly present the chemical composition of the $n$-pentane extracts of aromatic water obtained by $\mathrm{HD}$ and $\mathrm{DD}$ at $50^{\circ} \mathrm{C}$.

As it can be seen in Table 1 (fifth and sixth columns), the $n$-pentane extract of aromatic water of $R$. canina showed a different composition pattern depending on the distillation method. In both samples, alcohols had the highest contribution of the total extract and the main components were eugenol and 2-phenethyl alcohol. The percentage of these components differed greatly with respect to the distillation method. In particular, eugenol was the most abundant component of the volatile oil obtained by HD (45.1\%) followed by 2-phenethyl alcohol (13.6\%), whereas they showed reciprocal trend when extracted by DD (58.4 and $23.7 \%$ for 2-phenethyl alcohol and eugenol, resp.).

The observed differences in the percentage of 2-phenethyl alcohol between the two distillation methods could be due to the loss of this component in the water because of its high solubility $(0.8 \mathrm{~g} / 100 \mathrm{~mL}$ in water) [17]. These authors reported that 2-phenethyl alcohol is better recovered by solvent extraction (60\%) when compared with hydrodistillation (1\%). Similarly, Babu et al. [18] found that the content of 2-phenethyl alcohol increased in dichloromethane extract of rose water compared to redistillation with water. In contrast, the higher eugeneol content in the hydodistilled aromatic water could be explained by its lower solubility in water and/or its higher volatility in steam. Evidence for this fact is given by Guan et al. [19], who found that steam distillation (SD) method was more efficient in the extraction of eugenol than hydrodistillation and soxhlet methods.

Alkanes and alkenes comprised $25.3 \%$ in the $n$-pentane extract of aromatic water obtained by HD whereas their percentage was reduced to approximately one fifth when obtained by DD. In both extract samples, this fraction was characterized by nonadecane, 1-heptadecene, and $n$-heneicosane as major components. On the other hand, some components like heptadecane, 1-nonadecene, tetracosane, pentacosane, and hexacosane were only extracted by HD.

The percentage of monoterpene hydrocarbons was generally lower in both extracts. This fraction consisted mainly of $\alpha$-pinene which was particularly more abundant in the extracts obtained by HD (3.5\%) than in those obtained by DD $(0.7 \%)$.

Among sesquiterpenes compounds, only the $\beta$-caryophyllene was detected in both extracts and its percentage was significantly higher in the HD extract $(2.6 \%)$. The other sesquiterpene hydrocarbons $\alpha$-guaiene and the oxygenated sesquiterpenes caryophyllene oxide were only extracted by HD.

The chemical composition of the essential oils of $R$. canina and other Rosa species from different locations has been previously reported $[6,16]$. In fact, alcohols known for their main contribution to the fragrance value of rose oils were reported as the most abundant chemical classes in $R$. damascena oils obtained by direct thermal desorption (DTD) and superheated water extraction (SWE) [20]. By using the latter technique (SWE), two years earlier, Özel and Clifford [6] reported that the essential oil of $R$. canina was mainly dominated by 2-phenethyl alcohol and benzyl alcohol. Volatile oil samples of $R$. damascena from India [21], France [22], and Iran [13] extracted by using liquidliquid extraction of the aromatic water, head-space, and hydrodistillation methods showed an aromatic profiles dominated by alcohols mainly 2-phenylethyl alcohol, citronellol, nerol, and geraniol, respectively. Another report from India reported that the essential oil obtained by the distillation of fresh flowers of $R$. damascena was dominated by alcohols (55.25-83.41\%) with 2-phenethyl alcohol being the main constituent [18]. In Iranian $R$. damascena, the essential oil extracted by hydrodistillation was found to be rich in $\beta$ citronellol (25.59\%) [23].

By using solid phase micro extraction-head space (SPME-HD), Rout et al. [17] showed that the essential oils of $R$. hybrida consisted predominantly of 2-phenylethyl alcohol, linalool, citronellol, nerol, and geraniol. Jirovetz et al. [24] used the same extraction procedure and found that citronellol (30.71\%), geraniol (16.11\%), and nerol (7.57\%) were the basic constituents of the essential oil of Chinese $R$. damascena.

The 2-phenylethyl alcohol and citronellol were reported as the major alcohols in the $n$-hexane extract of $R$. centifolia from Morocco [11]. The essential oil of R. brunonii obtained by hydrodistillation consisted mainly of eugenol, terpinen-4ol, geraniol, and citronellol [15].

On the other hand, the abundance of alkanes and alkenes in the essential oils of some Rosa species was previously reported $[25,26]$. An appreciable amounts of 2,6,11-trimethyl dodecane and eicosane was reported in $R$. canina oil obtained by SWE [6]. The octacosane and heneicosane are the major alkanes of the $R$. canina oil when extracted with soxhlet method as reported by these authors. Buschhaus et al. [27] reported that the alkanes were typical components of the epicuticular and intracuticular wax layer of $R$. canina leaves. In R. damascena oils obtained by DTD, SWE, and HD, 


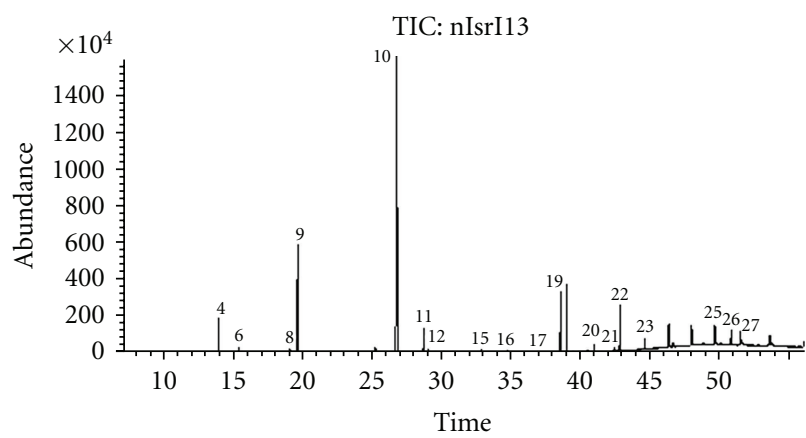

(a)

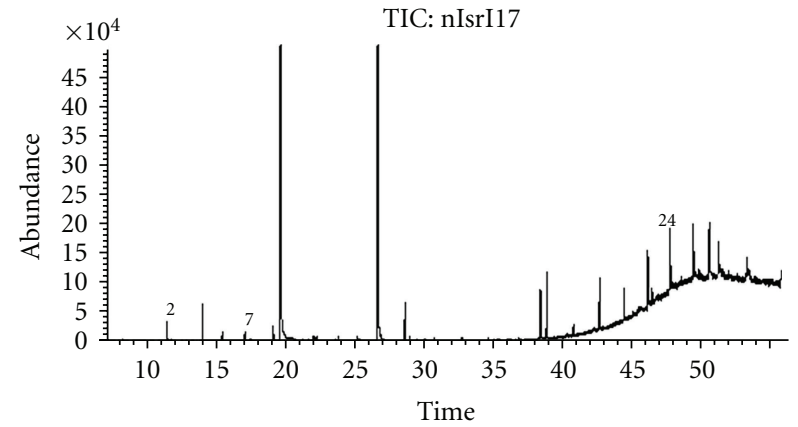

(b)

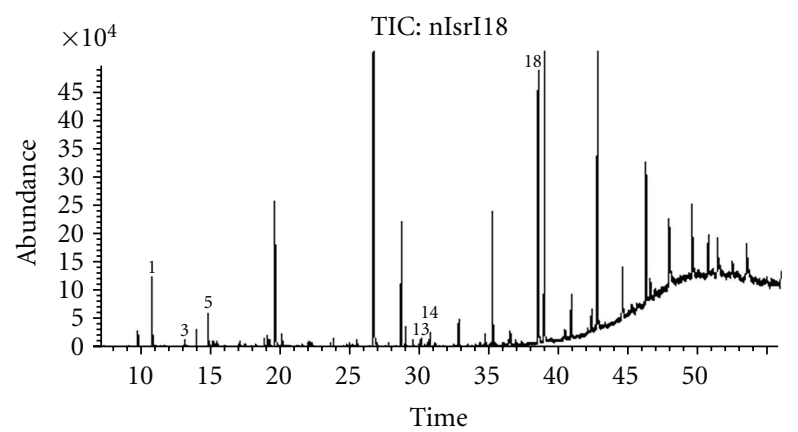

(c)

FIgure 1: Total Ion Chromatogram (TIC) of the essential oils of $R$. canina L. obtained by (a) HD, (b) DD at $50^{\circ} \mathrm{C}$ and (c) DD at $100^{\circ} \mathrm{C}$ (For peaks assignments, see Table 1).

this fraction was found with small percentages and dodecane, tridecane, tetradecane, 1-nonadecene, nonadecane, heneicosane, docosane, and octacosane were the major components [20]. Jalali-Heravi et al. [23] reported that eicosane $(29.88 \%)$, docosane $(14.07 \%), 1$-nonadecene $(6.54 \%)$, and heneicosane $(2.01 \%)$ were the major constituents of the alkanes/alkenes fraction in $R$. damascena from Iran.

Regarding the main group components, our results were in accordance with those previously reported for $R$. canina and other Rosa species such as $R$. damascena $[18,24]$. Nevertheless, qualitative and quantitative differences could be observed and may be related with the genetic background, biotic, and abiotic environmental factors, as well as the extraction methods and analytical conditions $[28,29]$. The influence of the extraction procedure on the qualitative and quantitative characteristics of the essential oil from different aromatic plants has been extensively investigated $[16,17,19$, 20,30]. For example, Özel et al. [20] compared the chemical composition of the essential oils of $R$. damascena obtained by DTD, SWE, and HD and found different compositional pattern depending on the extraction method. They reported that the oil obtained by HD was characterized by its high concentration of geraniol and citronellol, while theoils obtained by DTD and SWE were characterized by higher 2-phenethyl alcohol content. In a comparative analysis of the essential oil of lavandula obtained by solid-phase trapping solvent extraction (SPTE), headspace solid-phase microextraction (HD-SPME), reduced pressure stem distillation (RPSD), and simultaneous steam distillation-solvent extraction (SDE),
Kim and Lee [30] found that linalool and linalyl acetate account for $54.14 \%$ of the total oil obtained by SPTE, whereas their content ranged from 40.04 to $46.1 \%$ in the oils obtained by RPSD and SDE, respectively. The latter oils were characterized by their relative higher terpinen-4ol content. The essential oils of Calendula officinalis isolated by steam distillation comprised sesquiterpene hydrocarbons and oxygenated sesquiterpenes, while those obtained by HSSPME and headspace-cold finger (HD-CF) consisted only in sesquiterpene hydrocarbons [31]. More recently, Rout et al. [17] showed that the 2-phenethyl alcohol was better extracted by liquid $\mathrm{CO}_{2}$ of the fresh flowers of Mimusops elengi when compared with hydrodistillation and solvent extraction.

Interestingly, two alcohols, (E)-3-hexenol and benzyl alcohol, were only detected in the $n$-pentane extract of aromatic water obtained by DD. It can be suggested that these components occurred naturally in the volatile oil of $R$. canina, but they were only extracted at lower heating temperatures. In this way, Caissard et al. [22] found that the (E)-3-hexenol was a prominent component of $R$. damascena sepals. Benzyl alcohol has been identified in R. canina oil [6]. Cherri-Martin et al. [32] reported that the benzyl alcohol was rarely expressed or only present in trace amounts in roses oils. Another possible explanation to the absence of these components in the aromatic water obtained by distillation is their higher solubility in water and/or lower volatility in steam. Support to this assumption is given by Rout et al. [17], who showed that polar compounds mainly oxygenated 
TABLE 1: Chemical composition (\%) of the aromatic water of $R$. canina obtained by HD and DD at 50 and $100^{\circ} \mathrm{C}$.

\begin{tabular}{|c|c|c|c|c|c|c|}
\hline No & Compound & $\mathrm{RI}^{\mathrm{a}}$ & $\mathrm{RI}^{b}$ & \multicolumn{3}{|c|}{$(\%)$} \\
\hline & & & & $\mathrm{HD}$ & $\mathrm{DD} 50^{\circ} \mathrm{C}$ & $\mathrm{DD} 100^{\circ} \mathrm{C}$ \\
\hline 1 & 2,5-dimethylfuran & - & 1558 & - & - & $2,1^{\mathrm{a}}$ \\
\hline 2 & (E)-3-hexenol & 853 & 1391 & - & $0,4^{\mathrm{a}}$ & - \\
\hline 3 & 1-(2-furanyl)-ethanone & & 1494 & - & - & $0,3^{\mathrm{a}}$ \\
\hline 4 & $\alpha$-pinene & 940 & 1032 & $3,5^{\mathrm{a}}$ & $0,7^{\mathrm{b}}$ & 0,5 \\
\hline 5 & 5-methylfurfural & 964 & - & - & - & $1,1^{\mathrm{a}}$ \\
\hline 6 & $\beta$-pinene & 983 & 1118 & $0,7^{\mathrm{a}}$ & - & - \\
\hline 7 & benzyl alcohol & 1034 & 1896 & - & $0,2^{\mathrm{a}}$ & - \\
\hline 8 & linalool & 1088 & 1553 & $0,5^{\mathrm{a}}$ & $0,3^{\mathrm{a}}$ & - \\
\hline 9 & 2-phenethyl alcohol & 1117 & 1933 & $13,6^{\mathrm{b}}$ & $58,4^{\mathrm{a}}$ & $4,5^{\mathrm{c}}$ \\
\hline 10 & eugenol & 1356 & 2192 & $45,1^{\mathrm{a}}$ & $23,7^{b}$ & $22,9^{\mathrm{b}}$ \\
\hline 11 & $\beta$-caryophyllene & 1414 & 1612 & $2,6^{\mathrm{b}}$ & $0,7^{\mathrm{c}}$ & $3,3^{\mathrm{a}}$ \\
\hline 12 & $\alpha$-guaiene & 1440 & 1589 & $0,5^{\mathrm{a}}$ & - & $0,6^{\mathrm{a}}$ \\
\hline 13 & $\beta$-ionone & 1482 & 1952 & - & - & $0,3^{\mathrm{a}}$ \\
\hline 14 & $\delta$-guaiene & 1499 & 1723 & - & - & $0,4^{\mathrm{a}}$ \\
\hline 15 & caryophyllene oxide & 1576 & 2008 & $0,5^{\mathrm{a}}$ & - & - \\
\hline 16 & 8-heptadecene & 1666 & - & - & - & $6,8^{\mathrm{a}}$ \\
\hline 17 & 1-heptadecene & 1679 & - & $6,0^{\mathrm{a}}$ & $0,9^{\mathrm{b}}$ & - \\
\hline 18 & heptadecane & 1700 & 1698 & $0,4^{\mathrm{a}}$ & - & $0,4^{\mathrm{a}}$ \\
\hline 19 & 1-nonadecene & 1892 & - & $0,4^{\mathrm{b}}$ & - & $0,8^{\mathrm{a}}$ \\
\hline 20 & nonadecane & 1900 & 1897 & $6,5^{\mathrm{b}}$ & $1,1^{\mathrm{c}}$ & $10,1^{\mathrm{a}}$ \\
\hline 21 & $n$-eicosane & 2000 & 2000 & $0,6^{\mathrm{b}}$ & $0,21^{\mathrm{c}}$ & $3,4^{\mathrm{a}}$ \\
\hline 22 & $n$-heneicosane & 2100 & 2100 & $4,4^{\mathrm{b}}$ & $1^{\mathrm{c}}$ & $10,2^{\mathrm{a}}$ \\
\hline 23 & docosane & 2203 & 2200 & $1,0^{\mathrm{b}}$ & $0,9^{\mathrm{b}}$ & $1,9^{\mathrm{a}}$ \\
\hline 24 & tricosane & 2301 & 2300 & - & $1,3^{\mathrm{b}}$ & $4,2^{\mathrm{a}}$ \\
\hline 25 & tetracosane & 2398 & 2400 & $2,0^{\mathrm{a}}$ & - & - \\
\hline 26 & pentacosane & 2500 & 2500 & $2,7^{\mathrm{a}}$ & - & - \\
\hline 27 & hexacosane & 2598 & 2600 & $1,3^{\mathrm{a}}$ & - & 一 \\
\hline \multicolumn{7}{|c|}{ Group components } \\
\hline & Monterpene hydrocarbons & & & $4,2^{\mathrm{a}}$ & $0,7^{\mathrm{b}}$ & $0,5^{\mathrm{b}}$ \\
\hline & Sesquiterpenes hydrocarbons & & & $3,1^{b}$ & $0,7^{\mathrm{c}}$ & $4,3^{\mathrm{a}}$ \\
\hline & Oxygenated sesquiterpenes & & & $0,5^{\mathrm{a}}$ & - & $0,3^{\mathrm{a}}$ \\
\hline & Alkanes/alkenes & & & $25,3^{\mathrm{b}}$ & $5,4^{\mathrm{c}}$ & $37,8^{\mathrm{a}}$ \\
\hline & Alcohols & & & $59,3^{\mathrm{b}}$ & $83,0^{\mathrm{a}}$ & $27,4^{\mathrm{c}}$ \\
\hline & furan derivatives (O-heterocyclic) & & & - & - & $3,2^{\mathrm{a}}$ \\
\hline & Norisoprenoids & & & - & - & $0,3^{\mathrm{a}}$ \\
\hline & Total identified & & & $92,5 \%$ & $89,8 \%$ & $73,8 \%$ \\
\hline
\end{tabular}

* Retention Index relative to $n$-alkanes on $\left({ }^{a}\right)$ HP-5MS and $\left({ }^{b}\right)$ HP-Innowax columns.

terpenoids and benzenoids are more likely soluble in water. In our study, the absence of the (E)-3-hexenol and Benzyl alcohol in the hydrodistilled essential oil might be due to their loss in water because of their higher solubility (1.6 $\mathrm{g} / 100 \mathrm{~mL}$ and $4 \mathrm{~g} / 100 \mathrm{~mL}$ in water for $(E)$-3-hexenol and Benzyl alcohol, resp.).

\subsection{Effect of Temperature on the Chemical Composition of the} Aromatic Water. In order to give a direct view of the change on the chemical composition of the aromatic water, DD at excessive heating $\left(100^{\circ} \mathrm{C}\right)$ was carried out. The chemical composition and the TIC chromatogram are presented in Table 1 (seventh column) and Figure 1 (c), respectively.

As was expected, the $\mathrm{DD}$ at $100^{\circ} \mathrm{C}$ offered aromatic water with burnt odour impression and a total of 20 compounds belonging to 7 chemical classes were identified. The alkanes/alkenes fraction has the major contribution (37.8\%), and $n$-heneicosane, nonadecane, and 8 -heptadecene were the most abundant components. The other main chemical classes were found to be phenols with eugenol $(22.9 \%)$ as the major component. Alcohols with 2-phenylethyl alcohol $(4.5 \%)$ as the main component were found with appreciable 
percentages. Four sesquiterpene hydrocarbons with cumulative percentage of $4.6 \%$ were also detected. This fraction was dominated by $\beta$-caryophyllene. The norisoprenoid $\beta$-ionone had the lower contribution in the total extract.

The temperature increment seems to be associated with the appearance of furan derivatives which made up $3.2 \%$ of the total extract. These components including 2,5-dimethylfurane and 5-methylfurfural, derived from the degradation of carbohydrate via the Maillard reaction, could be responsible for the burnt odour impression [16, 33]. Consequently, the $\mathrm{DD}$ at moderate temperature $\left(50^{\circ} \mathrm{C}\right)$ is recommended since it ovoids the generation of these undesirable components providing hence, good oil quality. This is in good agreement with the results of Kapetanovic et al. [7].

In fact, it is recognized that the high quality of oil is closely related to a substantially higher amounts of oxygenated components and lower amounts of hydrocarbons $[20,34,35]$. Based on this criterion, it appeared that the DD at moderate heating is the best conventional method in terms of aromatic water quality. Moreover, its high efficiency for the extraction of highly odoriferous compounds such as 2phenethyl alcohol, eugenol, and benzyl alcohol [36] could support our suggestions.

Of interest, some identified components in this study have been advocated for their biological activities. Eugenol, for example, is a general acting antimicrobial and antianimal toxin with analgesic properties for humans. It is also used for food preservation and flavouring [37]. The 2-phenethyl alcohol, because of its rose-like aroma and its antifungal activity, is used as a fragrance ingredient in panoply of cosmetic products and foods such as beer, wine, olive oil, grapes, teas, apple juice, and coffee [38]. Moreover, the biological activities mainly antibacterial, anti-inflammatory, and anaesthetic have been shown by $\beta$-caryophyllene [39].

In summary, these data, once satisfactory toxicological information will be acquired, led to justify the traditional use of aromatic water of $R$. canina as functional extract.

\section{Acknowledgments}

The authors wish to thank Asma Allaoui (Laboratoire des Sciences de l'Environnement, Ecole Nationale d'Ingénieurs de Sfax, Tunisie) for the GC-MS analysis and Mme Radhia Mahjoubi (Ecole Supérieure d'Agriculture de Mograne, Zaghouan, Tunisia) for his precious technical help. They would also like to thank the Institution de Recherche et de l'Enseignement supérieur Agricol for its financial support of the research project (UR04AGR06).

\section{References}

[1] C. Chrubasik, B. D. Roufogalis, U. Müller-Ladner, and S. Chrubasik, "A systematic review on the Rosa canina effect and efficacy profiles," Phytotherapy Research, vol. 22, no. 6, pp. 725-733, 2008.

[2] S. Ercisli, "Chemical composition of fruits in some rose (Rosa spp.) species," Food Chemistry, vol. 104, no. 4, pp. 1379-1384, 2007.
[3] R. Nowak, "TLC fingerprinting analysis of the European dog rose," Journal of Planar Chromatography, vol. 20, no. 1, pp. 4348, 2007.

[4] S. R. Tabaei-Aghdaei, A. Babaei, M. Khosh-Khui et al., "Morphological and oil content variations amongst Damask rose (Rosa damascena Mill.) landraces from different regions of Iran," Scientia Horticulturae, vol. 113, no. 1, pp. 44-48, 2007.

[5] M. Shalit, I. Guterman, H. Volpin et al., "Volatile ester formation in roses. Identification of an acetyl-coenzyme A. Geraniol/citronellol acetyltransferase in developing rose petals," Plant Physiology, vol. 131, no. 4, pp. 1868-1876, 2003.

[6] M. Z. Özel and A. A. Clifford, "Superheated water extraction of fragrance compounds from Rosa canina," Flavour and Fragrance Journal, vol. 19, no. 4, pp. 354-359, 2004.

[7] S. Kapetanovic, S. Djugumovic, and R. Ramic, "Isolement de l'huile essentielle de rose par distillation sèche," Parfums Cosmetiques et Arômes, vol. 56, pp. 77-78, 1984.

[8] S. Teixeira, A. Mendes, A. Alves, and L. Santos, "Simultaneous distillation-extraction of high-value volatile compounds from Cistus ladanifer L," Analytica Chimica Acta, vol. 584, no. 2, pp. 439-446, 2007.

[9] K. Hosni, K. Msaâda, M. Ben Taârit, O. Ouchikh, M. Kallel, and B. Marzouk, "Essential oil composition of Hypericum perfoliatum L. and Hypericum tomentosum L. growing wild in Tunisia," Industrial Crops and Products, vol. 27, no. 3, pp. 308314, 2008.

[10] R. Adams, Identification of Essential Oil Components by Gas Ghromatography/Quadrupole Mass Spectroscopy, Allured Publ. Corp., Carol Stream, Ill, USA, 2001.

[11] T. Umezu, H. Ito, K. Nagano et al., "Anticonflict effects of rose oil and identification of its active constituents," Life Sciences, vol. 72, no. 1, pp. 91-102, 2002.

[12] H. E. M. Dobson, J. Bergström, G. Bergström, and I. Groth, "Pollen and flower volatiles in two Rosa species," Phytochemistry, vol. 26, no. 12, pp. 3171-3173, 1987.

[13] A. Almasirad, Y. Amanzadeh, A. Taheri, and M. Iranshahi, "Composition of a historical rose oil sample (Rosa damascena Mill., Rosaceae)," Journal of Essential Oil Research, vol. 19, no. 2, pp. 110-112, 2007.

[14] A. J. Al-Rehaily, T. A. Al-Howiriny, and H. R. Bizzo, "Essential oil of Rosa abyssinica R. Br. from Saudi Arabia," Journal of Essential Oil Research, vol. 15, no. 5, pp. 344-345, 2003.

[15] V. K. Kaul, R. K. Gujral, and B. Singh, "Volatile constituents of the essential oil of flowers of Rosa brunonii Lindl," Flavour and Fragrance Journal, vol. 14, no. 1, pp. 9-11, 1999.

[16] G. Bianchi, M. Nuzzi, A. A. Leva, and A. Rizzolo, "Development of a headspace-solid phase micro extraction method to monitor changes in volatile profile of rose (Rosa hybrida, cv David Austin) petals during processing," Journal of Chromatography A, vol. 1150, no. 1-2, pp. 190-197, 2007.

[17] P. K. Rout, D. Sahoo, and L. N. Misra, "Comparison of extraction methods of Mimusops elengi L. flowers," Industrial Crops and Products, vol. 32, pp. 678-680, 2010.

[18] K. G. D. Babu, B. Singh, V. P. Joshi, and V. Singh, "Essential oil composition of Damask rose (Rosa damascena Mill.) distilled under different pressures and temperatures," Flavour and Fragrance Journal, vol. 17, no. 2, pp. 136-140, 2002.

[19] W. Guan, S. Li, R. Yan, S. Tang, and C. Quan, "Comparison of essential oils of clove buds extracted with supercritical carbon dioxide and other three traditional extraction methods," Food Chemistry, vol. 101, no. 4, pp. 1558-1564, 2007.

[20] M. Z. Özel, F. Göğüş, and A. C. Lewis, "Comparison of direct thermal desorption with water distillation and superheated water extraction for the analysis of volatile components 
of Rosa damascena Mill. using GCxGC-TOF/MS," Analytica Chimica Acta, vol. 566, no. 2, pp. 172-177, 2006.

[21] S. G. Agarwal, A. Gupta, B. K. Kapahi, . Baleshwar, R. K. Thappa, and O. P. Suri, "Chemical composition of rose water volatiles," Journal of Essential Oil Research, vol. 17, no. 3, pp. 265-267, 2005.

[22] J. C. Caissard, V. Bergougnoux, M. Martin, M. Mauriat, and S. Baudino, "Chemical and histochemical analysis of 'Quatre Saisons Blanc Mousseux', a moss rose of the Rosa x damascena group," Annals of Botany, vol. 97, no. 2, pp. 231-238, 2006.

[23] M. Jalali-Heravi, H. Parastar, and H. Sereshti, "Development of a method for analysis of Iranian damask rose oil: combination of gas chromatography-mass spectrometry with Chemometric techniques," Analytica Chimica Acta, vol. 623, no. 1, pp. 11-21, 2008.

[24] L. Jirovetz, G. Buchbauer, A. Stoyanova, A. Balinova, Z. Guangjiun, and M. Xihan, "Solid phase microextraction/gas chromatographic and olfactory analysis of the scent and fixative properties of the essential oil of Rosa damascena L. from China," Flavour and Fragrance Journal, vol. 20, no. 1, pp. $7-12,2005$.

[25] N. Marekov, B. Stoïanova-Ivanova, L. Mondeshky, and G. Zolotovitch, "Biogenesis of alkanes in the flowers of the essential oil rose (Rosa damascena Mill.)," Phytochemistry, vol. 7, no. 2, pp. 231-234, 1968.

[26] E. Basim and H. Basim, "Antibacterial activity of Rosa damascena essential oil," Fitoterapia, vol. 74, no. 4, pp. 394396, 2003.

[27] C. Buschhaus, H. Herz, and R. Jetter, "Chemical composition of the epicuticular and intracuticular wax layers on adaxial sides of Rosa canina leaves," Annals of Botany, vol. 100, no. 7, pp. 1557-1564, 2007.

[28] N. Dudai, Z. G. Weinberg, O. Larkov, U. Ravid, G. Ashbell, and E. Putievsky, "Changes in essential oil during enzymeassisted ensiling of lemongrass (Cymbopogon citratus Stapf.) and lemon eucalyptus (Eucalyptus citriodora Hook)," Journal of Agricultural and Food Chemistry, vol. 49, no. 5, pp. 22622266, 2001.

[29] G. Sacchetti, A. Medici, S. Maietti et al., "Composition and functional properties of the essential oil of Amazonian basil, Ocimum micranthum Willd., Labiatae in comparison with commercial essential oils," Journal of Agricultural and Food Chemistry, vol. 52, no. 11, pp. 3486-3491, 2004.

[30] N. S. Kim and D. S. Lee, "Comparison of different extraction methods for the analysis of fragrances from Lavandula species by gas chromatography-mass spectrometry," Journal of Chromatography A, vol. 982, no. 1, pp. 31-47, 2002.

[31] Z. C. Gazim, C. M. Rezende, S. R. Fraga, B. P. D. Filho, C. V. Nakamura, and D. A. G. Cortez, "Analysis of the essential oils from Calendula officinalis growing in Brazil using three different extraction procedures," Brazilian Journal of Pharmaceutical Sciences, vol. 44, no. 3, pp. 391-395, 2008.

[32] M. Cherri-Martin, F. Jullien, P. Heizmann, and S. Baudino, "Fragrance heritability in Hybrid Tea roses," Scientia Horticulturae, vol. 113, no. 2, pp. 177-181, 2007.

[33] C. W. Ho, W. M. W. Aida, M. Y. Maskat, and H. Osman, "Changes in volatile compounds of palm sap (Arenga pinnata) during the heating process for production of palm sugar," Food Chemistry, vol. 102, no. 4, pp. 1156-1162, 2007.

[34] V. Fernández-Pérez, M. M. Jiménez-Carmona, and M. D. Luque de Castro, "An approach to the static-dynamic subcritical water extraction of laurel essential oil: comparison with conventional techniques," Analyst, vol. 125, no. 3, pp. 481-485, 2000.
[35] M. E. Lucchesi, F. Chemat, and J. Smadja, "Solvent-free microwave extraction of essential oil from aromatic herbs: comparison with conventional hydro-distillation," Journal of Chromatography A, vol. 1043, no. 2, pp. 323-327, 2004.

[36] M. Sakai, H. Hirata, H. Sayama et al., "Production of 2phenylethanol in roses as the dominant floral scent compound from L-phenylalanine by two key enzymes, a PLP-dependent decarboxylase and a phenylacetaldehyde reductase," Bioscience, Biotechnology and Biochemistry, vol. 71, no. 10, pp. 2408-2419, 2007.

[37] T. Koeduka, E. Fridman, D. R. Gang et al., "Eugenol and isoeugenol, characteristic aromatic constituents of spices, are biosynthesized via reduction of a coniferyl alcohol ester," Proceedings of the National Academy of Sciences of the United States of America, vol. 103, no. 26, pp. 10128-10133, 2006.

[38] E. K. Mo and C. K. Sung, "Phenylethyl alcohol (PEA) application slows fungal growth and maintains aroma in strawberry," Postharvest Biology and Technology, vol. 45, no. 2, pp. 234-239, 2007.

[39] B. Sabulal, M. Dan, A. J. John et al., "Caryophyllene-rich rhizome oil of Zingiber nimmonii from South India: chemical characterization and antimicrobial activity," Phytochemistry, vol. 67, no. 22, pp. 2469-2473, 2006. 


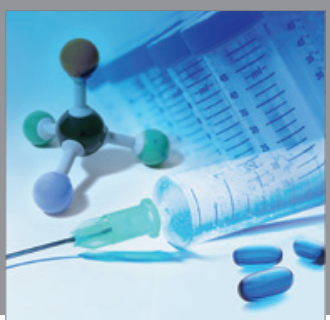

International Journal of

Medicinal Chemistry

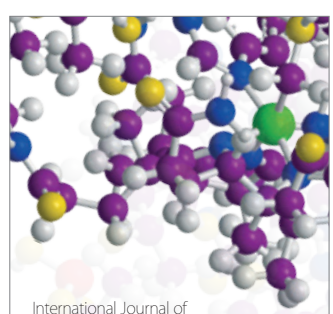

Carbohydrate Chemistry

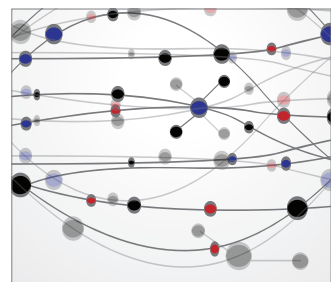

The Scientific World Journal
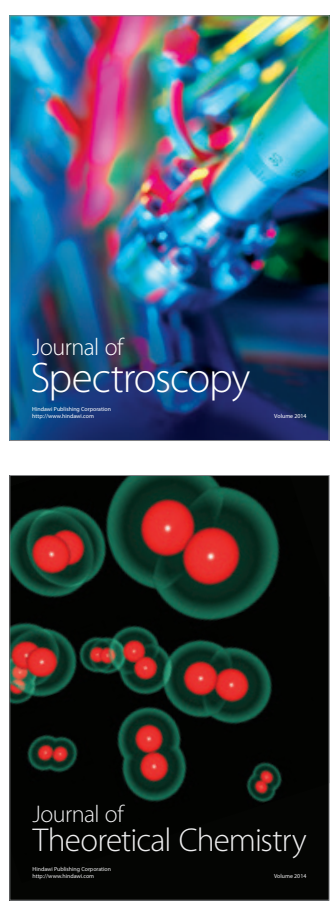
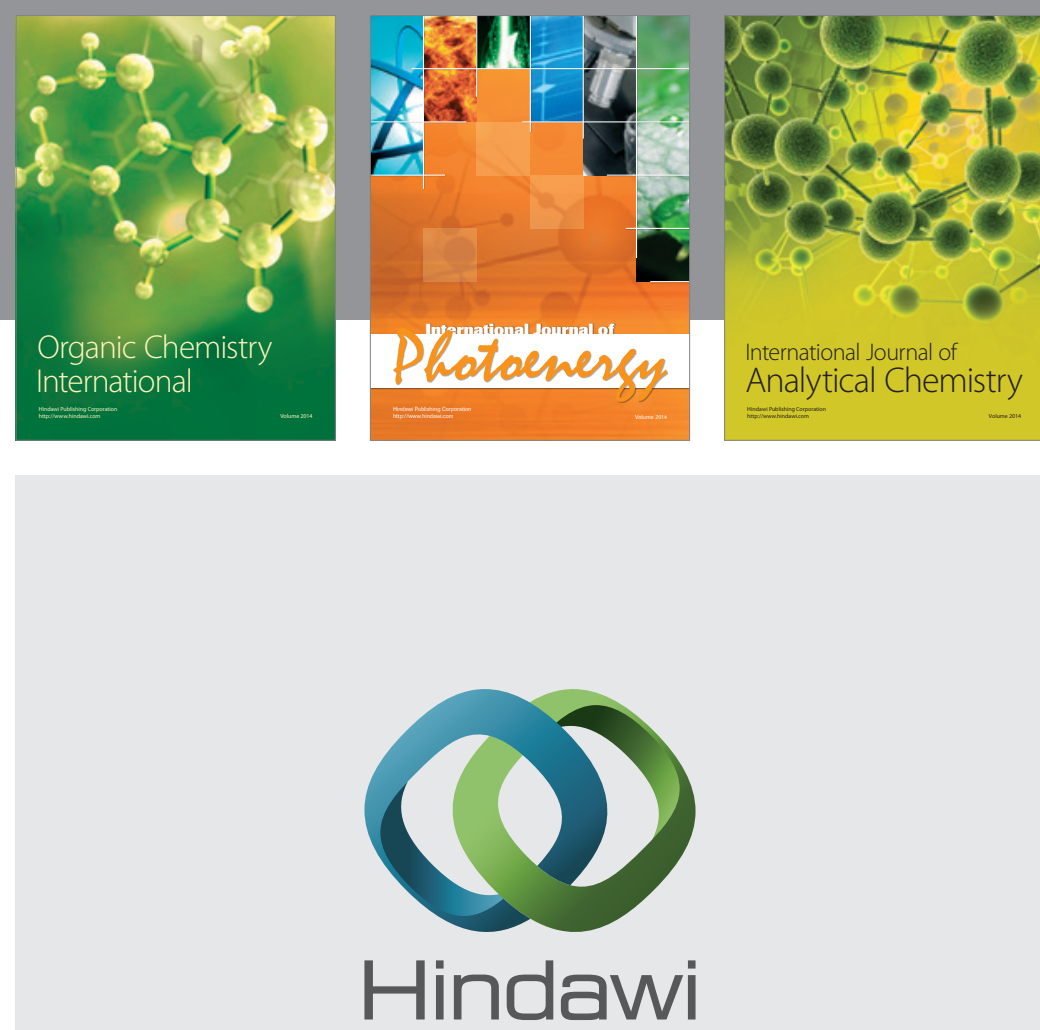

Submit your manuscripts at

http://www.hindawi.com
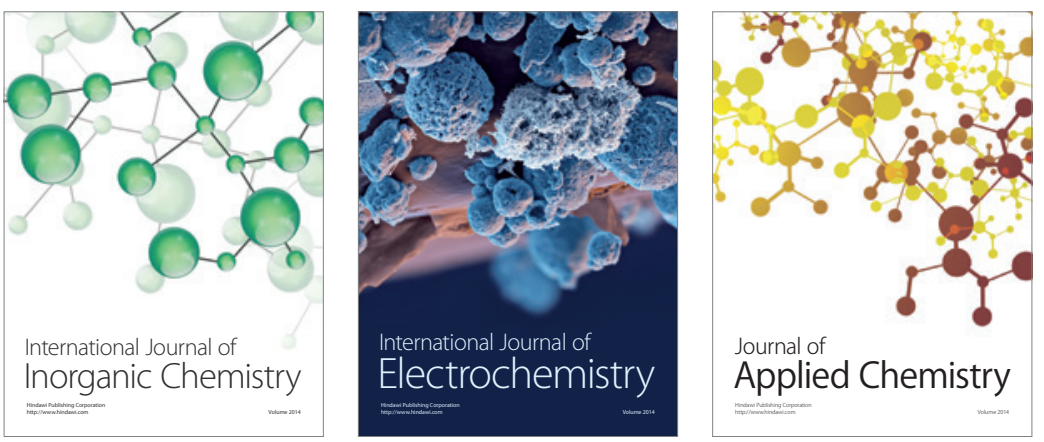

Journal of

Applied Chemistry
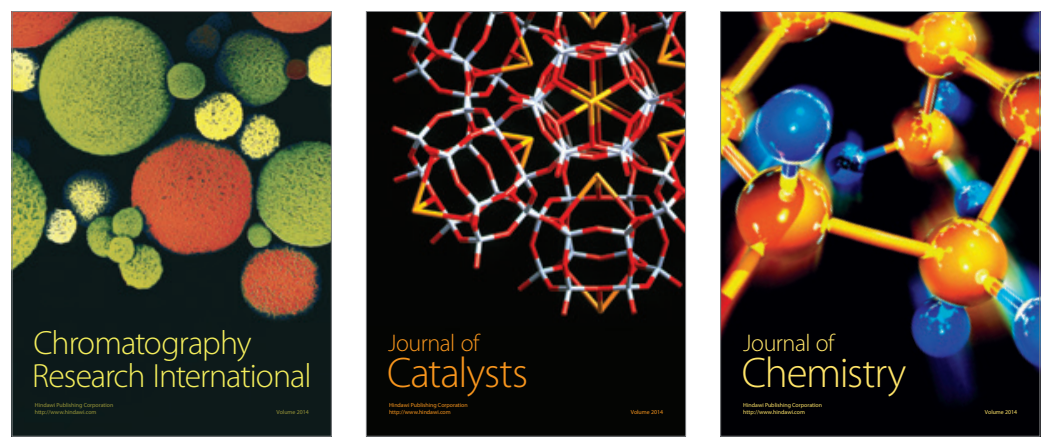
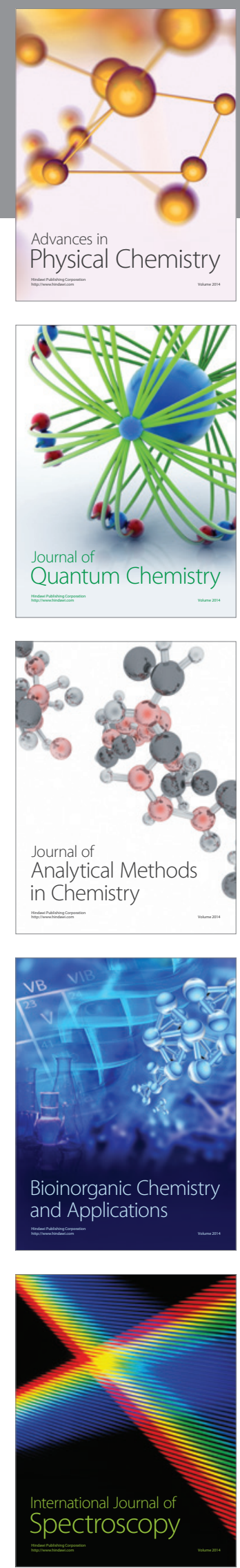